\title{
The Internal Morphology and Composition of a Purple Pigment Particle Extracted from an Ancient Faiyum Mummy Portrait
}

\author{
Glenn Gates ${ }^{1}$, Darryl Butt ${ }^{2}$, Jatuporn Burns ${ }^{3,4}$, Yaqiao $\mathrm{Wu}^{3,4}$, Gordon Alanko ${ }^{3}$, Jennifer K Watkins ${ }^{3}$ \\ 1. Walters Art Museum, Department of Conservation and Technical Research, Baltimore, USA. \\ 2. College of Mines and Earth Sciences, University of Utah, Salt Lake City, USA. \\ 3. Micron School of Materials Science and Engineering, Boise State University, Boise, USA. \\ ${ }^{4 .}$ Center for Advanced Energy Studies, Idaho Falls, USA.
}

The painting in the collection of the Walters Art Museum (WAM), Baltimore, Maryland titled Mummy Portrait of a Bearded Man WAM\#32.6 attributed to Roman-occupied Egypt (ca. 170-180 CE) was examined as part of an ongoing international research initiative focused on the characterization of the materials used to create ancient mummy portraits, a collaboration referred to as the APPEAR Project [1]. During stereoscopic examination of this painting, unusually large, approximately $2 \mathrm{~mm}$ diameter, rough gem-like purple particles were identified throughout the painted clavi, or the purple toga stripes on the shoulders used to indicate individuals of high social stature. With exposure to long-wave ultraviolet radiation $(315 \mathrm{~nm}-400 \mathrm{~nm})$, the paint used for the clavi appeared pink-orange, suggesting the use of an organic colorant. Analyses at WAM of the clavi paint using air-path, energy dispersive X-ray fluorescence (XRF) equipped with a micro-focus polycapillary lens, suggested the purple particles contained lead, aluminum, titanium, silicon, potassium, iron and probably sulfur with, surprisingly, chromium at concentrations estimated in the parts-per-thousand range. To better characterize the unusual purple particles, a sample of the paint used for the clavi was removed. The sample contained one rough gem-like purple particle; this singular purple particle was analyzed by scientists affiliated with Boise State University using SEM, TEM, STEM-HAADF and EDS techniques.

The sample from the clavi on the Walters' Portrait of a Bearded Man was first analyzed using SEMEDS, and the results suggested the purple particle is primarily organic, with approximately a minimum 80 atomic-percent carbon content. This finding was consistent with the long wave ultraviolet radiation inspection of the portrait that suggested the presence of a laked pigment in the clavi, that is, a pigment formed by affixing an organic colorant onto an inorganic substrate. Next, a TEM sample of the particle was prepared using a focused ion beam (FIB), as shown in Figure 2. To the authors' knowledge, the result of the FIB milling reveals the first-ever visualization of the internal, cross-sectional structure of an ancient laked pigment, imaged by STEM-HAADF in Figure 2 and imaged by TEM in Figure 3.

The most surprising finding was the extent of morphological structure within the lake pigment particle that was resolved on the nanoscale; specifically three notable features were observed. The low density, continuous matrix $(\alpha)$ was rich in aluminum and sulfur, as would be expected for a laked pigment produced using an aluminum salt, commonly potash alum $\mathrm{KAl}\left(\mathrm{SO}_{4}\right)_{2} \cdot 12 \mathrm{H}_{2} \mathrm{O}$ [2]. Unexpectedly, leadcontaining nanoparticles were identified, distributed throughout the laked pigment, having either irregular/spherical shape $(\gamma)$ and containing more lead than aluminum, or needle shape $(\beta)$ and containing more aluminum than lead. Two lead-containing nanoparticles were identified as lead sulfate using electron diffraction, and appear to have precipitated during lake formation. While the source of lead remains speculation, the authors suggest a lead-lined vat used for dyeing fabrics might be one reasonable source of the lead, as excavated by Petrie [3]. This might then suggest that the purple used for this mummy portrait may evidence ancient upcycling- the reuse of dyer's sludge as paint pigment [4]. 


\section{References:}

[1] The Ancient Panel Painting: Examination, Analysis and Research [APPEAR] Project was established in 2013 by Marie Svoboda, Conservator of Antiquities at the J. Paul Getty Museum, see http://www.getty.edu/museum/research/appear_project/

[2] V Daniels et al, British Museum Technical Research Bulletin 8 (2014), p. 17.

[3] F Petrie in "Athribis" 1908. (School of Archaeology University College, London) p.11.

[4] The authors gratefully acknowledge funding from The Andrew W. Mellon Foundation. Julie Lauffenburger and Elizabeth LaDuc are thanked for their many discussions of this research.

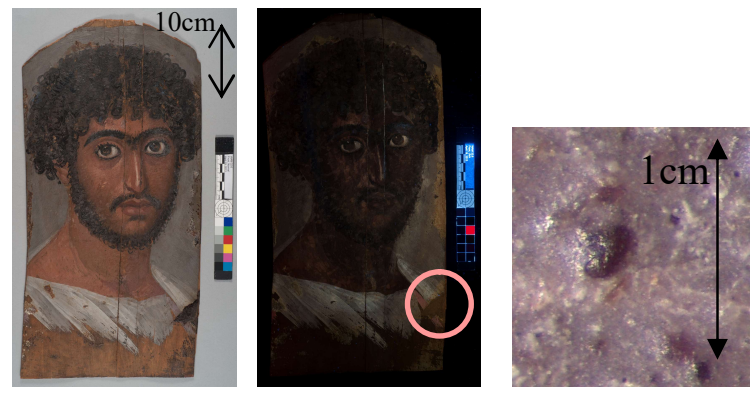

Figure 1. The Walters' Portrait of a Bearded Man under visible light, under long-wave UV radiation showing the pink-orange clavi, and the large, rough gem-like purple particles in the clavi.
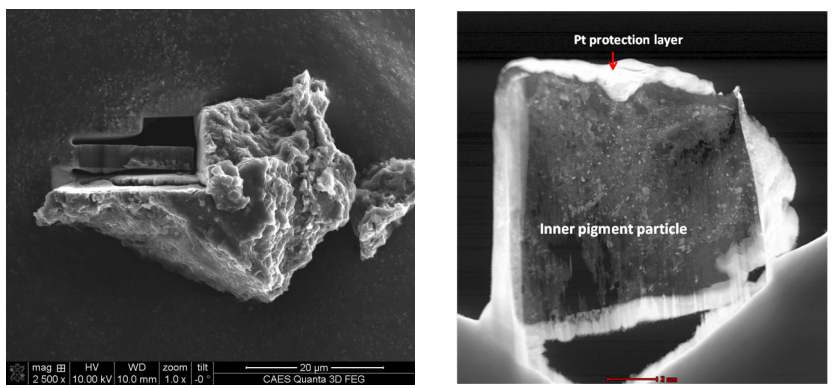

Figure 2. The sample as extracted from the Portrait of a Bearded Man after FIB milling, and the result of the FIB milling with the complete sample particle interior morphology imaged using STEM-HAADF.
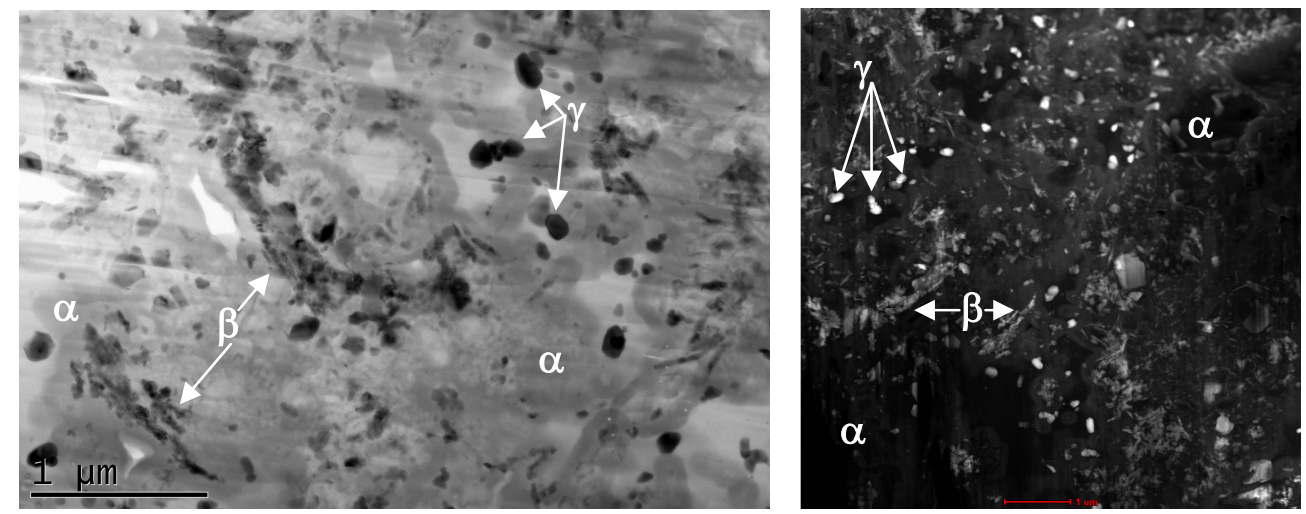

Figure 3. TEM bright-field image showing three morphologies of different composition: light gray, low density, continuous matrix $(\alpha)$; dark, high density, irregular/spherical particles $(\gamma)$; and needle-shaped particles of moderate density ( $\beta$ ); STEM-HAADF image of the same features (with opposite contrast). 